\title{
PROJETO DE EXTENSÃO - CIDADES INTELIGENTES: DESENVOLVIMENTO DE SOLUÇÕES IOT PARA AS CIDADES
}

DOI: 10.37702/2175-957X.COBENGE.2021.3701

Lucas Silvestre Chaves - lucas.chaves@prof.una.br

Centro Universitário UNA de Betim

Rua Courupita 605

32310-520 - Contagem - MG

PATRICIA MARIA SOARES - PATRICIA_MS14@HOTMAIL.COM

Centro Universitário UNA de Contagem

RUA BUENOS AIRES 424

30315-570 - BELO HORIZONTE - MG

Thiago Henrique Chaves Batista - thiagohenriquec.batista@gmail.com

Centro Universitário UNA de Betim

Benedito Dias dos Santos 304

32606-522 - Betim - MG

Bruno Castro Braga - bcastrobraga@gmail.com

Centro Universitário UNA de Contagem

rua limeira 110

32010-420 - Contagem - MG

Resumo: Este trabalho tem como objetivo apresentar uma metodologia de desenvolvimento de soluções IoT aplicada na condução do projeto de extensão "Cidades Inteligentes" durante o primeiro ano da pandemia. Diante dos desafios impostos pelo novo coronavírus, o uso de plataformas digitais e simuladores online foi fundamental para a condução do projeto. Os encontros virtuais e as oficinas de capacitação foram realizadas por meio de videoconferências online e foi criada uma sala de aula virtual para acompanhamento das atividades do projeto. Como resultados, sete soluções foram desenvolvidas por equipes interdisciplinares, compostas por alunos dos cursos de Engenharia, Tecnologia e Arquitetura. Os dois melhores projetos foram selecionados e apresentaram suas soluções na Mostra de Extensão, evento institucional aberto ao público. Além do conhecimento técnico, o projeto de extensão estimulou o empreendedorismo e o aprimoramento de habilidades interpessoais, como cooperação, disciplina e proatividade. 


\section{COBENCE E Evento onine

Palavras-chave: Cidades Inteligentes, Internet das Coisas, Projeto de Extensão, Tecnologias Digitais, Interdisciplinaridade, Pandemia 


\section{PROJETO DE EXTENSÃO - CIDADES INTELIGENTES: DESENVOLVIMENTO DE SOLUÇÕES IOT PARA AS CIDADES}

\section{INTRODUÇÃO}

O surgimento de novas tecnologias é um processo irreversível que tem interferência direta na vida pessoal e profissional da sociedade. Hoje é comum ver pessoas na rua ou no transporte público conectadas à Internet, trabalhando ou se socializando, por meio de um celular ou até mesmo por um relógio. Estima-se que 35 bilhões de dispositivos estejam conectados à rede mundial até 2025 , gerando um mercado de oportunidades de 11,1 trilhões de dólares por ano até esta data (LAPER, 2020). Tecnologias como Internet das Coisas (loT, Internet of Things), Big Data e Inteligência Artificial (Al, Artificial Intelligence) têm possibilitado o desenvolvimento de soluções que melhoram a forma de produzir das indústrias (SACOMANO et al, 2018) e a qualidade de vida nas cidades (DE MORAIS, 2018).

Uma Cidade Inteligente é aquela em que seus elementos se conectam, permitindo soluções de monitoramento e controle, tais como: a otimização de recursos hídricos e energéticos, monitoramento de enchentes, combate ao incêndio, aprimoramento da segurança, melhoria do tráfego nas cidades, entre outros (NETO, 2019). O projeto de extensão "Cidades Inteligentes", conduzido nos dois semestres de 2020, teve como principais objetivos capacitar e motivar alunos dos diferentes cursos de Engenharia, de Tecnologia e de Arquitetura a desenvolverem soluções que pudessem contribuir para a transformação de uma cidade em uma "Cidade Inteligente".

Alinhado ao conceito de aprendizagem significativa (DA COSTA et al, 2019), o projeto de extensão em questão visou preparar os alunos para o novo mercado de trabalho através: do conhecimento e da aplicação de novas tecnologias, da estimulação do perfil empreendedor, do aprimoramento de habilidades interpessoais e da conscientização do papel do profissional na melhoria da sociedade.

\section{REFERENCIAL TEÓRICO}

A definição de uma cidade inteligente não é uma tarefa simples pois deve considerar a composição diversificada de uma sociedade que é constituída por três campos distintos: as ciências sociais, as ciências exatas e as ciências biológicas (NETO, 2019). Diversos estudos têm sido realizados com objetivo de criar uma definição abrangente de cidade inteligente. De acordo com a União Internacional de Telecomunicações (UIT), uma cidade inteligente pode ser definida da seguinte forma

"Uma cidade sustentável inteligente é uma cidade inovadora que utiliza as TIC e outros meios para melhorar a qualidade de vida, eficiência da operação e serviços urbanos, e competitividade, assegurando ao mesmo tempo atender às necessidades de gerações presentes e futuras no que diz respeito aos aspectos econômicos, sociais e ambientais" (ONU, 2015, p.1).

\subsection{Projeto de extensão}

De acordo com o Art. $3^{\circ}$ da Resolução № 7, de 18 de dezembro de 2018

"A Extensão na Educação Superior Brasileira é a atividade que se integra à matriz curricular e à organização da pesquisa, constituindo-se em processo interdisciplinar, político educacional, cultural, científico, tecnológico, que promove a interação transformadora entre as instituições de ensino superior e os outros setores da sociedade, por meio da produção e da aplicação do 
conhecimento, em articulação permanente com o ensino e a pesquisa" (Brasil, 2018).

O Art. $8^{\circ}$ da Resolução N 7, de 18 de dezembro de 2018 (Brasil, 2018) por sua vez descreve que as atividades de extensão, seguindo os projetos políticos pedagógicos dos cursos, devem se inserir nas seguintes modalidades: programas, projetos, cursos e oficinas e prestação de serviços.

O projeto de extensão "Cidades Inteligentes" alinha-se as diretrizes supracitadas nos parágrafos anteriores, uma vez que teve como objetivos principais capacitar e motivar alunos de diferentes cursos de Engenharia, Tecnologia e Arquitetura, a desenvolverem soluções interdisciplinares que visam melhorar a qualidade de vida das pessoas da sociedade em geral.

\subsection{Interdisciplinaridade nas soluções das cidades}

Os problemas encontrados em uma cidade são interdisciplinares por natureza. As soluções desses problemas portanto necessitam de equipes de profissionais de diferentes áreas, tais como: engenheiros, arquitetos, profissionais de $\mathrm{TI}$, de saúde, de administração, etc. O estudo de caso do processo de transformação da cidade suíça de St. Gallen em uma cidade inteligente (GASSMANN et al, 2019), descreve que as responsabilidades no desenvolvimento dos projetos devem ser atribuídas a diferentes departamentos. $O$ estudo diz ainda que, aproveitar a complexidade da estrutura administrativa do município possibilita diversas abordagens para a solução dos problemas, pois raramente há apenas uma maneira de ver as coisas. A Figura 1 mostra a Matriz de Responsabilidades da iniciativa St. Gallen Smart City, que ilustra como as responsabilidades foram distribuídas entre diferentes departamentos no desenvolvimento das soluções inteligentes através de uma matriz de responsabilidades.

Figura 1 - Matriz de Responsabilidades da iniciativa

St. Gallen Smart City.

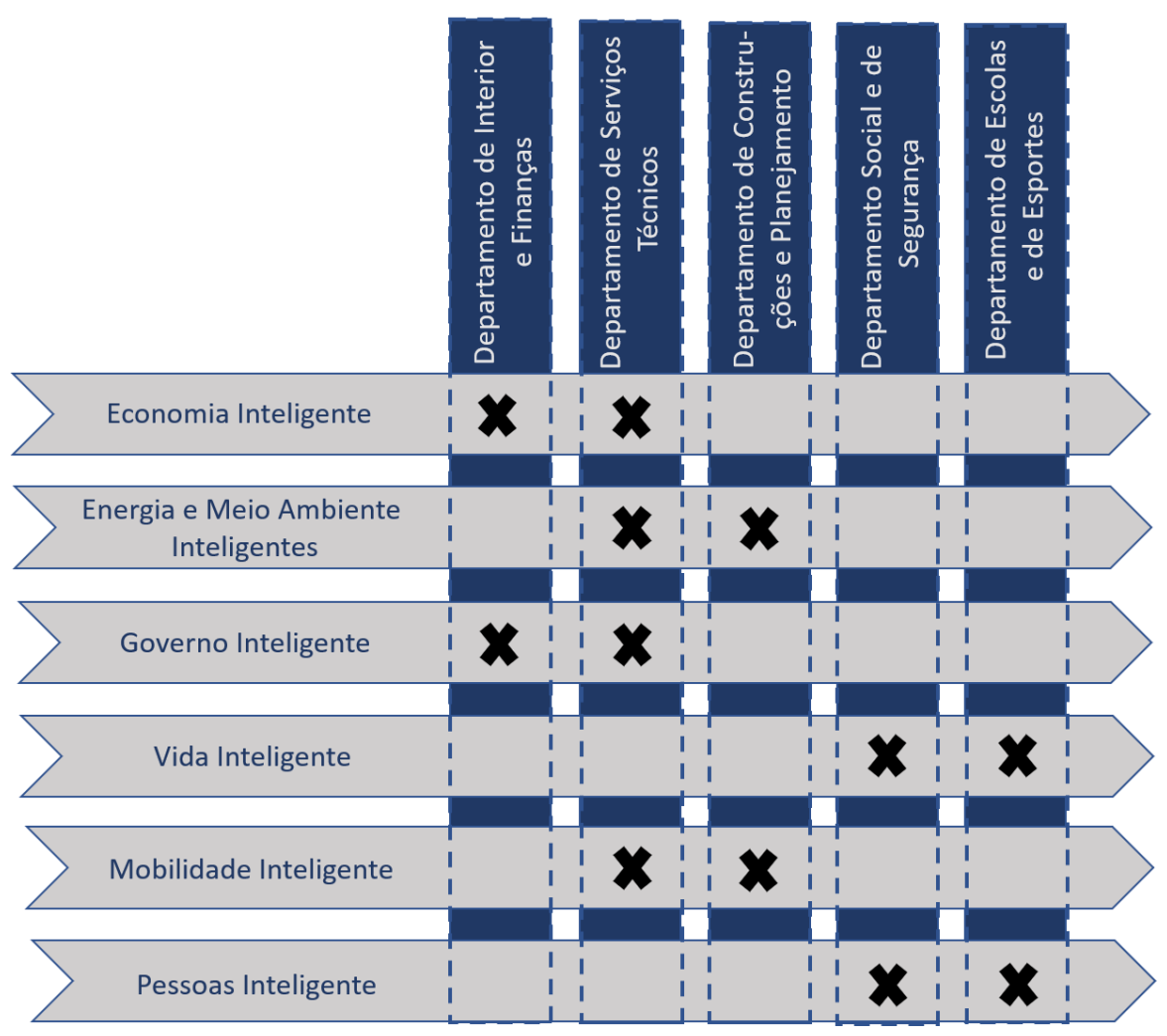

Fonte: Adaptado de GASSMANN et al, 2019. 


\subsection{Tecnologias digitais para ensino e aprendizagem}

O uso das tecnologias digitais no processo de ensino e aprendizagem tem sido uma alternativa predominante frente aos desafios impostos pelo novo coronavírus, apesar de esbarrar em problemas como a falta de acessibilidade e de formação específica para o uso dessas ferramentas (DA SILVA et al, 2020). De acordo com BAXTO (2019), ambientes educacionais abastecidos pelas TIC (Tecnologia da Informação e da Comunicação), principalmente aqueles estruturados para atividades colaborativas, podem desenvolver um tipo de inteligência compartilhada.

Para o acompanhamento das atividades do projeto "Cidades Inteligentes" e realização das oficinas de capacitação, foram utilizadas plataformas digitais de ensino e aprendizagem. Os encontros remotos foram realizados em uma plataforma de videoconferência online. Uma sala de aula virtual foi criada para troca de informações, compartilhamento de material e acompanhamento das atividades do projeto.

\subsection{Oficinas de capacitação}

As oficinas de capacitação auxiliam os alunos no aprendizado de fundamentos científicos, conceitos e tecnologias através da prática e da experimentação. De acordo com DA COSTA (2019), as atividades práticas incentivam a criatividade e a curiosidade enquanto que a experimentação, juntamente ao debate, estimula o pensamento crítico e inovador dos alunos. Em termos virtuais, a prática e a experimentação podem ser realizadas por meio de simuladores.

No projeto de extensão discutido no presente artigo, foram realizadas três oficinas de capacitação, com objetivo de apoiar as equipes no desenvolvimento de suas soluções. $\mathrm{Na}$ sequência, estão apresentadas breves descrições dos assuntos e das ferramentas utilizadas em cada uma dessas oficinas.

\section{Sistemas Microcontrolados com Arduino}

Sistemas microcontrolados são sistemas eletrônicos programados para realizar aplicações específicas (TOCCl et al, 2018). Nas aplicações de loT, estes sistemas atribuem aos objetos da rede a capacidade de sensoriamento, armazenamento, processamento e transmissão de dados, dando-Ihes o nome de "objetos inteligentes" (SANTOS et al, 2016). Para a implementação dos objetos inteligentes foi escolhido o Arduino, que consiste em uma família de placas de prototipagem eletrônica de hardware e software abertos vastamente utilizadas por estudantes e entusiastas de tecnologias no desenvolvimento de sistemas microcontrolados (BANZI et al, 2015). Para as oficinas virtuais de Arduino foi utilizado o ambiente de simulação de circuitos eletrônicos gratuito conhecido como Tinkercad (TINKERCAD, 2021).

\section{Desenvolvimento de Aplicativos com Applnventor}

A ferramenta utilizada na oficina de desenvolvimento de aplicativos foi o Applnventor (MIT APP INVENTOR, 2021), desenvolvido pelo MIT (Massachusetts Institute of Technology). Essa é uma ferramenta online e gratuita, em que o desenvolvimento dos programas é baseado em montagem de blocos, o que torna desnecessário o conhecimento prévio de programação para o uso da ferramenta. Salienta-se que os aplicativos desenvolvidos pelo Applnventor só rodam em dispositivos onde o sistema operacional é o Android. 


\section{Introdução à Internet das Coisas}

A Internet das Coisas pode ser definida como a conexão de todas as "coisas", tais como objetos, animais, pessoas e sistemas, com objetivo de realizar aplicações que melhoram o cotidiano das pessoas em suas casas, no trabalho, na cidade ou no planeta como um todo (JUNIOR et al, 2018). Além de apresentar os fundamentos de loT, a oficina de Internet das Coisas tem como objetivo ensinar aos alunos como estabelecer uma comunicação via Internet entre o aplicativo de celular e os objetos inteligentes utilizando o protocolo MQTT (Message Queue Telemetry Transport) (JUNIOR et al, 2018), que é um protocolo de comunicação com servidor descentralizado, específico para aplicações loT.

\section{METODOLOGIA}

Inicialmente foi realizado um processo de inscrição online no projeto de extensão, organizado pela coordenação de extensão da instituição de ensino. Posteriormente, um processo de seleção foi realizado pelo próprio coordenador do projeto. O critério de seleção era basicamente o curso em que o aluno inscrito estava matriculado, que priorizava os cursos de Engenharia e de Tecnologia. Não havia restrição para períodos. Após a seleção dos alunos, criou-se um grupo em uma plataforma de troca de mensagens instantâneas para fins de comunicação. Criou-se também uma sala de aula virtual para o armazenamento de informações relacionados ao projeto de extensão, tais como: links de sites, cronograma, apresentações e atividades. Os encontros do projeto foram realizados por videoconferências, nas manhãs dos sábados, de 09:00 às 11:00. A Tabela 1 apresenta o cronograma dos encontros e das atividades desenvolvidas no projeto durante o segundo semestre de 2020.

Tabela 1 - Cronograma de encontro e atividades do projeto de extensão "Cidades Inteligentes" $-2^{\circ}$ semestre de 2020.

\begin{tabular}{|c|c|c|}
\hline Encontro & Tema & Atividade da Semana \\
\hline $1^{\circ}$ & $\begin{array}{c}\text { Palestra sobre } \\
\text { Cidades Inteligentes }\end{array}$ & --- \\
\hline $2^{\circ}$ & Encontro Inicial. & $\begin{array}{l}\text { - Fazer um estudo sobre possíveis aplicações } \\
\text { existentes dentro de uma Cidade Inteligente. } \\
\text { - Definir o grupo e a solução a ser desenvolvida } \\
\text { no projeto. }\end{array}$ \\
\hline $3^{\circ}$ & $\begin{array}{c}\text { Oficina de Introdução } \\
\text { aos Sistemas } \\
\text { Microcontrolados } \\
\text { com Arduino. }\end{array}$ & $\begin{array}{l}\text { - Compreender como o ARDUINO poderia ser } \\
\text { utilizado na solução do problema proposto pelo } \\
\text { grupo. } \\
\text { - Fazer um levantamento dos possíveis } \\
\text { sensores e atuadores a serem utilizados no } \\
\text { projeto. }\end{array}$ \\
\hline $4^{\circ}$ & Mão na massa! & $\begin{array}{l}\text { - Fazer um desenho ou diagrama do projeto que } \\
\text { apresente uma visão sistêmica geral da } \\
\text { aplicação, destacando os principais elementos } \\
\text { e descrevendo suas funções. } \\
\text { - Implementar uma simulação do ARDUINO } \\
\text { atuando na solução proposta pelo grupo } \\
\text { através da leitura de sensores, acionamento } \\
\text { de atuadores, etc.. }\end{array}$ \\
\hline
\end{tabular}




\begin{tabular}{|c|c|c|}
\hline $5^{\circ}$ & $\begin{array}{c}\text { Oficina de Introdução } \\
\text { ao Desenvolvimento } \\
\text { de Aplicativos com } \\
\text { Applnventor; }\end{array}$ & $\begin{array}{l}\text { - Descrever as funcionalidades do sistema de } \\
\text { supervisão do projeto. }\end{array}$ \\
\hline $6^{\circ}$ & Mão na massa! & $\begin{array}{l}\text { - Desenvolver um aplicativo no Applnventor } \\
\text { para supervisionar a aplicação. A sugestão é } \\
\text { que o app. possua três telas: } \\
\checkmark \text { Tela 1: Tela de Login e Senha; } \\
\checkmark \text { Tela 2: Tela de Supervisão e controle; } \\
\checkmark \text { Tela 3: Tela de Históricos e Relatórios. }\end{array}$ \\
\hline $7^{\circ}$ & $\begin{array}{l}\text { Oficina de Introdução } \\
\text { à Internet das Coisas. }\end{array}$ & $\begin{array}{l}\text { - Desenhar a arquitetura IoT da solução } \\
\text { proposta definindo os seguintes elementos da } \\
\text { arquitetura: } \\
\checkmark \text { Objetos Inteligentes; } \\
\checkmark \text { Redes; } \\
\checkmark \text { Aplicação Final. }\end{array}$ \\
\hline $8^{\circ}$ & Mão na massa! & $\begin{array}{l}\text { - Incluir no aplicativo do projeto funções de } \\
\text { armazenamento e leitura de dados na nuvem. }\end{array}$ \\
\hline $9^{\circ}$ & $\begin{array}{l}\text { Orientações sobre a } \\
\text { apresentação. }\end{array}$ & $\begin{array}{l}\text { - Desenvolver uma apresentação do trabalho } \\
\text { desenvolvido pelo grupo de } 10 \text { a } 15 \text { minutos. }\end{array}$ \\
\hline $10^{\circ}$ & $\begin{array}{l}\text { Exposição dos } \\
\text { protótipos } \\
\text { desenvolvidos. }\end{array}$ & $\begin{array}{l}\text { - Melhorar a apresentação com base nas } \\
\text { sugestões de melhoria propostas pelo } \\
\text { professor e pela banca. }\end{array}$ \\
\hline $11^{\circ}$ & Mostra da Extensão & $\begin{array}{l}\text { - Preencher o formulário final do projeto } \\
\text { (realizado pelo professor). }\end{array}$ \\
\hline
\end{tabular}

Fonte: Própria Autoria.

Um especialista da área foi convidado para abrir o projeto de extensão com uma palestra sobre Cidades Inteligentes. Nesta palestra, foram apresentados os conceitos básicos relacionados ao tema em questão. No fim da palestra, solicitou-se que os alunos fizessem uma reflexão sobre possíveis problemas encontrados nas cidades que poderiam ser resolvidos com a aplicação da Internet das Coisas. Após a palestra, foi enviado aos alunos um formulário digital para o cadastro de temas e dos respectivos grupos de trabalho. As perguntas do formulário estão apresentadas no Quadro 1:

Quadro 1 - Perguntas do formulário digital para o cadastro de temas e grupos.

\begin{tabular}{|c|c|}
\hline $\mathrm{N}^{\circ}$ & Pergunta \\
\hline 1 & Qual é o tema (título) do projeto proposto pelo grupo? \\
\hline 2 & Digite o nome completo de cada um dos integrantes do grupo (máximo 8): \\
\hline 3 & Qual é a cidade que vocês gostariam de transformar em uma "Cidade Inteligente"? \\
\hline 4 & $\begin{array}{l}\text { Que problema vocês gostariam de resolver que possa contribuir para a } \\
\text { transformação da cidade escolhida em uma "Cidade Inteligente"? }\end{array}$ \\
\hline 5 & $\begin{array}{c}\text { Como a Internet das Coisas poderia ser utilizada para solucionar o problema } \\
\text { apresentado? }\end{array}$ \\
\hline 6 & Luais seriam as melhorias esperadas com a implementação do projeto propos \\
\hline
\end{tabular}

Fonte: Própria Autoria. 
A Tabela 2 apresenta o tema e uma breve descrição dos principais projetos trabalhados pelos alunos em grupos dentro do projeto de extensão durante o segundo semestre de 2020.

Tabela 2 - Projetos desenvolvidos dentro do projeto de extensão "Cidades Inteligentes" durante o primeiro e o segundo semestre de 2020.

\begin{tabular}{|c|c|}
\hline Tema & Descrição \\
\hline $\begin{array}{l}\text { Sensor para Detecção de } \\
\text { Vazamentos de Gás } \\
\text { Residencial }\end{array}$ & $\begin{array}{l}\text { Consiste em um sistema capaz de detectar } \\
\text { vazamentos de gás de cozinha e alertar ao } \\
\text { usuário por meio de um aplicativo de celular, } \\
\text { com o objetivo de trazer mais segurança aos } \\
\text { moradores de uma residência e prevenir } \\
\text { acidentes. }\end{array}$ \\
\hline $\begin{array}{l}\text { Lava-Jato Ecológico } \\
\text { Automatizado }\end{array}$ & $\begin{array}{l}\text { Sistema automatizado de reutilização da água } \\
\text { cinza em Lava-Jatos com monitoramento e } \\
\text { controle remotos realizado por aplicativo de } \\
\text { celular. }\end{array}$ \\
\hline $\begin{array}{l}\text { SSI - Sistem } \\
\text { Segurança Intel }\end{array}$ & $\begin{array}{l}\text { Sistema de segurança eletrônica com } \\
\text { monitoramento de câmeras loT e transmissão } \\
\text { de alerta de invasão às autoridades e usuários } \\
\text { cadastrados. }\end{array}$ \\
\hline $\begin{array}{r}\text { Solução lo } \\
\text { Monitoramen } \\
\text { do Rio }\end{array}$ & $\begin{array}{l}\text { Solução loT para o monitoramento do nível do } \\
\text { rio Betim e envio de alertas sobre riscos de } \\
\text { transbordamentos e de alagamentos das } \\
\text { comunidades vizinhas. }\end{array}$ \\
\hline $\begin{array}{l}\text { HELPING HAND - o app } \\
\text { em solidariedade a quem } \\
\text { precisa }\end{array}$ & $\begin{array}{l}\text { O HELPING HAND auxilia na busca por } \\
\text { pessoas que estão dispostas a doar alimentos } \\
\text { próximas a você caso você esteja buscando } \\
\text { ajuda. Já se é você quem deseja doar, o } \\
\text { HELPING HAND te auxilia a encontrar quem } \\
\text { esteja buscando ajuda, além de te oferecer um } \\
\text { serviço de entrega caso você não possa } \\
\text { entregar. }\end{array}$ \\
\hline $\begin{array}{c}\text { Controle e } \\
\text { Monitoramento do Fluxo } \\
\text { de Pessoas em } \\
\text { Estabelecimentos } \\
\text { Fechados }\end{array}$ & $\begin{array}{l}\text { Com objetivo de minimizar os impactos e } \\
\text { reduzir os riscos de infecção causados pela } \\
\text { Covid } 19 \text {, o grupo propôs o desenvolvimento de } \\
\text { uma solução loT capaz de monitorar as } \\
\text { temperaturas e controlar a quantidade de } \\
\text { pessoas dentro de estabelecimentos fechados. }\end{array}$ \\
\hline Smart Green & $\begin{array}{l}\text { A Smart Green consiste em um projeto da } \\
\text { promoção do ecoturismo no meio urbano, que } \\
\text { como consequência, apresenta uma alternativa } \\
\text { de transporte para a população através da } \\
\text { criação de ciclovias, e uma forma de combate } \\
\text { ao fenômeno das ilhas de calor através da } \\
\text { criação de jardins botânicos com sistemas de } \\
\text { irrigação inteligentes. }\end{array}$ \\
\hline
\end{tabular}


A Figura 2 refere-se à uma foto do sistema desenvolvido pela equipe do projeto com o tema "Solução loT para o Monitoramento Remoto do Rio Betim". Os itens indicados pelos números 1 e 2 na figura, referem-se às interfaces de monitoramento do rio visualizadas no computador e no celular respectivamente. $\mathrm{O}$ destaque de número 3 , indica o módulo de telemetria do sistema, constituído por um módulo Wi-Fi (ESP32), por um sensor ultrassônico para medições de níveis (hc-sr04) e por um medidor de temperatura e de umidade (DHT11). O item de número 4, apresenta uma plataforma elevatória para simulação dos níveis do rio. O nível do rio, a umidade do ar e a temperatura são parâmetros atualizados na interface de monitoramento em tempo real através da Internet, em forma de mensagens e de gráficos. Combinações dessas informações também são analisadas para gerar alertas sobre riscos de transbordamentos do rio e de alagamentos das comunidades vizinhas.

Figura 2 - Solução loT para o Monitoramento Remoto do Rio Betim.
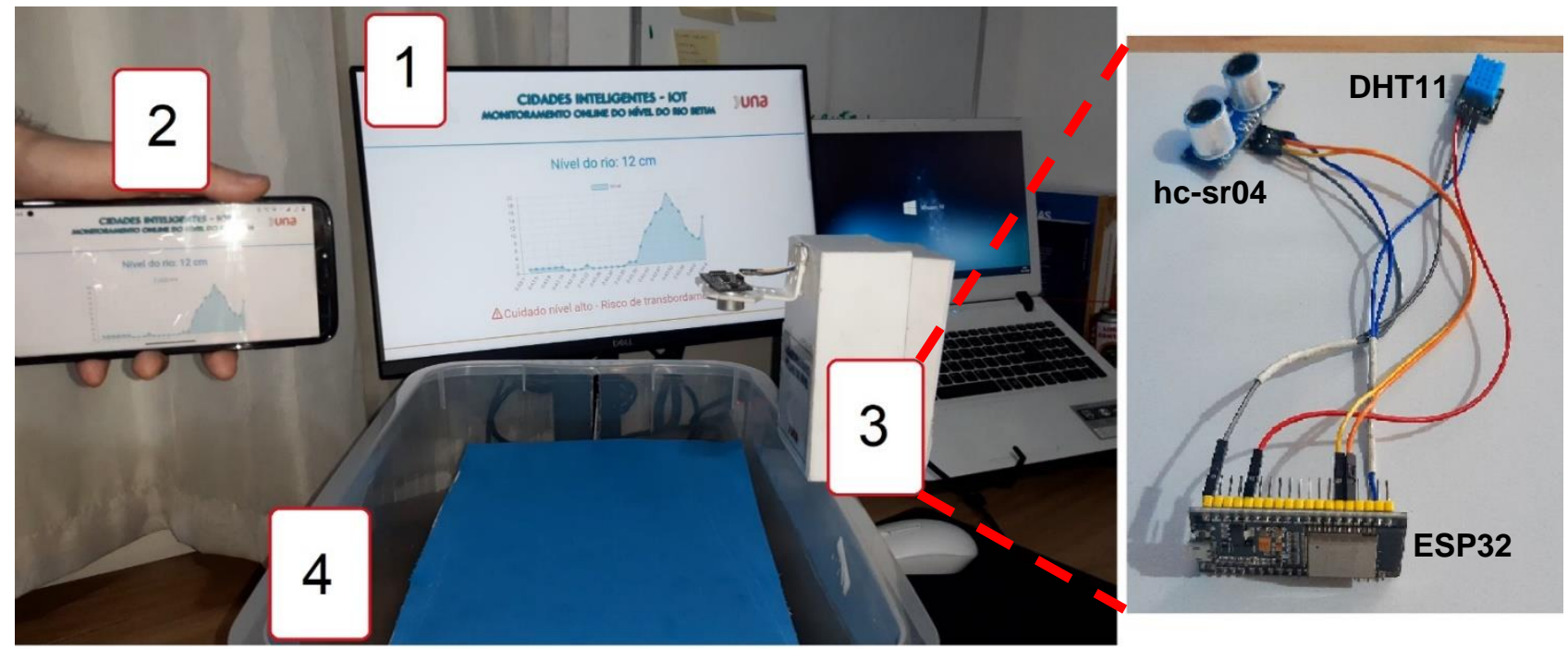

Fonte: Própria Autoria.

Ressalta-se que encontros presenciais e testes das soluções nas cidades não foram etapas contempladas pelo projeto de extensão devido ao contexto de pandemia vivenciado em 2020 no qual os projetos foram elaborados. Contudo, a utilização das plataformas digitais de ensino, além de softwares online de simulação e de criação, como o Tinkercard e o Applnventor, permitiram a criação de protótipos pelos grupos.

Foram ofertadas três oficinas de capacitação que apoiaram o desenvolvimento dos projetos: Introdução aos Sistemas Microcontrolados com Arduino; Desenvolvimento de Aplicativos com Applnventor e Introdução à Internet das Coisas. Entre as oficinas, ocorreram as reuniões denominadas "Mão na Massa!", cujo o objetivo era dar continuidade nas oficinas e acompanhar o desenvolvimento dos projetos.

Além dos encontros aos sábados, os alunos realizavam atividades semanais que auxiliavam no desenvolvimento do projeto. A realização e entrega dessas atividades validavam as horas complementares da semana (6 horas). Essas atividades estão descritas em detalhes na terceira coluna da Tabela 1.

No $10^{\circ}$ encontro, os grupos fizeram a exposição de suas soluções através de apresentações por videoconferências com durações de 10 a 15 minutos. Um professor de Sistema de Informação (R.B.) e um ex. aluno de Engenharia Elétrica (M.R.) foram convidados para assistir o trabalho com a tarefa de selecionarem as duas melhores 
apresentações. Os projetos selecionados foram: "Controle e Monitoramento do Fluxo de Pessoas em Estabelecimentos Fechados" e "Solução loT para o Monitoramento Remoto do Rio Betim". Os trabalhos selecionados representaram o projeto de extensão" no evento institucional aberto ao público designado por "Mostra de Extensão". Foram etapas importantes do projeto, em que os alunos puderam expor seus trabalhos, trocar experiências, receber sugestões e traçar os próximos passos.

\section{$4 \quad$ RESULTADOS}

Participaram do projeto de extensão "Cidades Inteligentes" durante o ano de 2020, 83 alunos de diferentes cursos de Engenharia (Civil, Elétrica, Mecânica e Produção), de Tecnologia (Sistemas de Informação, Análise e Desenvolvimento de Sistema, Ciência da Computação e Automação) e de Arquitetura. Os alunos participantes tiveram três oficinas de capacitação durante a execução do projeto, em que os conceitos assimilados foram implementados nas soluções propostas por eles. Todos os alunos, em grupos, apresentaram suas soluções através de apresentações por videoconferência. Sete grupos conseguiram atingir o objetivo de desenvolver soluções em diferentes áreas, em que dois projetos se destacaram: "Controle e Monitoramento do Fluxo de Pessoas em Estabelecimentos Fechados" e "Solução loT para o Monitoramento Remoto do Rio Betim".

A utilização das plataformas digitais de ensino, além de softwares de simulação e de criação de aplicativos gratuitos e online, permitiu que todas as atividades planejadas para o projeto pudessem ser realizadas virtualmente. Em adição, o uso dessas ferramentas permitiu também que todos os encontros fossem gravados e disponibilizados na sala virtual do projeto, para consultas e estudos posteriores por parte dos alunos. Além das gravações, links de sites com informações relevantes e materiais utilizados durante os encontros também foram disponibilizados na sala de aula virtual. $O$ uso dessas ferramentas permitiu transmitir aos alunos os fundamentos de novas tecnologias, capacitá-los em oficinas, trocar experiências, apresentar soluções e disseminar o conhecimento para a comunidade através da Mostra de Extensão.

Através das palestras e das oficinas realizadas durante o projeto, os alunos estudaram tecnologias relevantes para a formação profissional de cada um deles, tais como sistemas microcontrolados, desenvolvimento de aplicativos, Internet das Coisas e Cidades Inteligentes. Esses conhecimentos ajudam a integrar os alunos em um mercado cada vez mais tecnológico, competitivo e dinâmico. Além do conhecimento técnico, o presente projeto estimulou o aprimoramento de habilidades interpessoais como cooperação, disciplina, empatia, automotivação e proatividade. Por fim, o projeto motivou os alunos a buscarem novos conhecimentos, estimulou o empreendedorismo e aumentou a sensação de pertencimento dos alunos com a instituição.

Para verificar a contribuição do projeto "Cidades Inteligentes" na vida acadêmica e profissional de alunos que já participaram do projeto foi realizada a seguinte pergunta para eles: Como sua participação no projeto "Cidades Inteligentes" pode ter contribuído para a melhoria de suas habilidades e competências acadêmicas e profissionais? O aluno T. H. C. respondeu:

"No período de 2020 participei do projeto de extensão Cidades Inteligentes. Durante as oficinas, tive a oportunidade de aprimorar e colocar em prática meus conhecimentos obtidos durante o curso, tais como, eletrônica, lógica de programação, redes e Internet das coisas. Desta forma, pude entender a integração destas disciplinas atuando no processo de solucionar problemas atuais de nossas cidades, tornando nossa vida mais segura, inteligente e tecnológica através dos conceitos de loT".

O aluno B. C. B. enviou a seguinte resposta: 
"O projeto de extensão abordou tecnologias atuais e incentivou o uso delas através de reuniões práticas virtuais, onde podíamos aplicar os conhecimentos adquiridos. Além do conhecimento técnico, o trabalho em grupo gerou uma oportunidade de melhorar o trabalho em equipe e as habilidades sociais, nos preparando para um mercado de trabalho interdisciplinar".

\section{CONSIDERAÇÕES FINAIS}

O projeto de extensão "Cidades Inteligentes" foi idealizado com o objetivo principal de capacitar tecnicamente os alunos das diferentes Engenharias e cursos de Tecnologias a desenvolverem soluções que possam contribuir para a transformação das cidades em "Cidades Inteligentes". Os resultados obtidos, após dois semestres de realização, revelaram um potencial muito maior do que inicialmente previsto, demonstrando ser um projeto interdisciplinar, pois atraiu alunos de outras áreas do conhecimento como Arquitetura e Urbanismo. De fato, os problemas encontrados nas cidades são interdisciplinares, e necessitam de profissionais de diversas áreas para serem resolvidos. A experiência obtida por esses alunos trouxe para eles algo além dos conhecimentos técnicos adquiridos. Os alunos puderem constatar que o respeito, a dedicação, 0 companheirismo e a cooperação entre diferentes profissionais são fatores essenciais para o desenvolvimento de soluções que podem transformar as cidades em lugares melhores para se viver.

Há dois caminhos traçados para a continuidade do projeto de extensão aqui discutido: replicar o modelo atual para novos alunos interessados no projeto; dar continuidade com os alunos já participantes, com objetivo de aprimorar as soluções já apresentadas e realizar testes nas cidades assim que possível.

\section{REFERÊNCIAS}

BANZI, Massimo; SHILOH, Michael. Primeiros Passos com o Arduino - 2ª Edição: A plataforma de prototipagem eletrônica open source. 2. Ed, Novatec Editora, 2015.

BAXTO, Welinton; CARNEIRO, Vânia Lúcia Quintão. Uso das TIC na educação superior a distância. Educação, v. 42, n. 1, p. 35-43, 2019.

CONSELHO NACIONAL DE EDUCAÇÃO (Brasil). Resolução n 7, de 18 de dezembro de 2018. Diário Oficial da União, Brasília, 19 dez. 2018. Seção 1, p. 49. Disponível em: https://www.in.gov.br/materia/-/asset publisher/Kujrw0TZC2Mb/content/id/55877808.

Acesso em: 13 mai. 2021.

DA COSTA, Maria Marta Ribeiro et al. Interação entre alunos do ensino médio e das engenharias através do ATEC. Brazilian Journal of Development, v. 5, n. 10, p. 1964419657, 2019.

DA SILVA, Chayene Cristina Santos Carvalho; DE SOUSA TEIXEIRA, Cenidalva Miranda. O uso das tecnologias na educação: os desafios frente à pandemia da COVID-19. Brazilian Journal of Development, v. 6, n. 9, p. 70070-70079, 2020.

DE MORAIS, Izabelly Soares et al. Introdução a Big Data e Internet das Coisas (IoT). Porta Alegre: SAGAH. 2018. 
GASSMANN, Oliver; BÖHM, Jonas; PALMIÉ, Maximilian. Smart Cities: Introducing Digital Innovation to Cities. United Kingdom: Emerald Group Publishing, 2019.

JUNIOR, Sergio Luiz Stevan. Internet das coisas: fundamentos e aplicações em Arduino e Node MCU. 1. Ed, São Paulo: Érica, 2018.

LAPER, D. A Revolução das Coisas - Contexto nacional e global de loT, 14 abr. 2020. Disponível em: https://abinc.org.br/a-revolucao-das-coisas-contexto-nacional-e-global-deiot/\#: :text=Segundo\%20estudos\%20da\%20Mckinsey\%20(3,vezes\%20a\%20popula\%C3 \%A7\%C3\%A30\%20mundial\%20hoje). Acesso em: 14 mai. 2021.

MIT APP INVENTOR. Tutorials for MIT App Inventor, c2021. Disponível em: https://appinventor.mit.edu/explore/ai2/tutorials. Acesso em: 16 mai. 2021.

NETO, Vicente Soares. CIDADES INTELIGENTES: Guia para Construção de Centros Urbanos Eficientes e Sustentáveis. 1. Ed, São Paulo: Érica, 2019.

ORGANIZAÇÃO DAS NAÇÕES UNIDAS (ONU). Documentos temáticos da Habitat III. Cidades Inteligentes, 31 mai 2015. Disponível em: http://habitat3.org/wpcontent/uploads/21-Cidades-Inteligentes final.pdf. Acesso em: 13 mai. 2021.

SACOMANO, José Benedito et al. Indústria 4.0. Editora Blucher, 2018.

SANTOS, Bruno P. et al. Internet das coisas: da teoria à prática. Minicursos SBRCSimpósio Brasileiro de Redes de Computadores e Sistemas Distribuıdos, v. 31, 2016.

TINKERCAD. Circuits, c2021. Disponível em: https://www.tinkercad.com/learn/circuits. Acesso em: 17 mai. 2021.

TOCCI, Ronald J. et al. Sistemas digitais: princípios e aplicações. 12. Ed, São Paulo: Pearson Education do Brasil, 2018.

\title{
EXTENSION PROJECT - SMART CITIES: DEVELOPMENT OF IOT SOLUTIONTS FOR CITIES
}

\begin{abstract}
This work has as objective to present a methodology of development of loT solutions applied in the conduction of the extension project Smart Cities during the first year of the pandemic. In view of the challenges imposed by new coronavirus, the use of digital platforms and online simulators was fundamental for the conduct of the project. The virtual meetings and the training workshops were performed by online videoconferences and a virtual classroom was created to monitor the project's activities. As a result, seven loT solutions were developed by interdisciplinary teams, composed of students from the Engineering, Technology and Architecture courses. The two best projects were selected to present their solutions at the "Mostra de Extensão", an institutional event open to the public. In addition to technical knowledge, this project stimulated entrepreneurship and the improvement of soft skills, such as cooperation, discipline and proactivity.
\end{abstract}

Keywords: Smart Cities, Internet of Things, Extension Project, Digital Technology, Interdisciplinarity, Pandemic. 